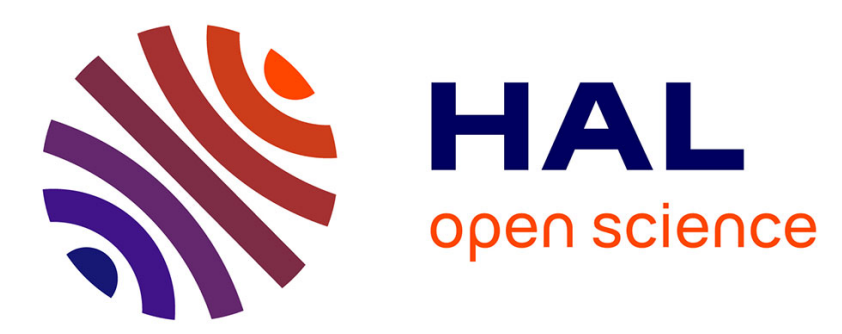

\title{
Material characterisation to identify the rheological behaviour for powder injection moulding
}

Dimitri Claudel, Mohamed Lakdhar Sahli, Thierry Barriere, Jean Gelin

\section{To cite this version:}

Dimitri Claudel, Mohamed Lakdhar Sahli, Thierry Barriere, Jean Gelin. Material characterisation to identify the rheological behaviour for powder injection moulding. International Powder Metallurgy Conference and Exhibition, Jun 2014, Ankara, Turkey. hal-02300561

\section{HAL Id: hal-02300561 https://hal.science/hal-02300561}

Submitted on 29 Sep 2019

HAL is a multi-disciplinary open access archive for the deposit and dissemination of scientific research documents, whether they are published or not. The documents may come from teaching and research institutions in France or abroad, or from public or private research centers.
L'archive ouverte pluridisciplinaire HAL, est destinée au dépôt et à la diffusion de documents scientifiques de niveau recherche, publiés ou non, émanant des établissements d'enseignement et de recherche français ou étrangers, des laboratoires publics ou privés. 


\title{
Dimitri Claudel, Mohamed Sahli, Thierry Barrière, Jean-Claude Gelin
}

FEMTO-ST Institute/Applied Mechanics, Besançon, France

\section{Material characterisation to identify the rheological behaviour for powder injection moulding}

\author{
Paper presented at "7 $7^{\text {th }}$ International Powder Metallurgy Conference and Exhibition", \\ 24-28 June 2014, Gazi University, Ankara, Turkey
}

For the purpose of powder injection moulding, a specific method is presented to identify the parameters for a combined rheological constitutive model. This model is a combination of three models used in powder injection moulding and accounts for the effects of the temperature, shear rate and particle size of the powder. The data achieved in experimental measurements were used for identification of the model parameters. The model with identified parameters could be used to realize accurate simulations.

Keywords: Rheological model; Metal injection moulding; Inconel; Superalloy

\section{Introduction}

Metal injection moulding (MIM) is an economically attractive process for the production of small and complex metallic parts in large quantities. An advantage of this process is the direct production of complex, 3D, net-shaped components. Subsequent machining is rarely required. The final micro-components are used in a large range of applications, including in the medical, dental, aerospace, and automotive industries.

Studies on the powder injection moulding (PIM) process have achieved important advances in the last twenty years [1-4]. The dimensions and mechanical properties of MIM products are significantly affected by the feedstock characteristics and the process parameters of injection moulding, debinding and sintering.

For injection moulding of Inconel-based superalloys, the preparation of the feedstock of the Inconel-based superalloys is the most crucial stage. Sommer et al. [5] and Ahn et al. [6] showed the effects of the processing techniques and feedstock elaboration process on the material properties. Bilovol et al. [7] investigated the influence of the viscosity model via numerical simulation of the powder injection moulding process. Ui Moshin et al. [8] studied the influence of the solvent and thermal debinding parameters on the injected feedstock via thermo-analytical methods.

Numerical simulation of injection moulding is a very important method for designing the process and products. An accurate rheological model of the feedstock is crucial for a correct simulation. The feedstock is injected with large shear rates, up to $10^{5} \mathrm{~s}^{-1}$, under a temperature that may induce degradation of the polymer binder. The choice of a rheological model and the determination of its parameters should be made by the specifically designed tests with respect the same conditions in injection moulding.

In the present work, comparisons were made between experimental results and those obtained from analytical models.

Ratkovich et al. [9] showed several rheological models suitable for non-Newtonian materials to predict the apparent viscosity with different complexity. In the work of Senapati et al. [10], a constitutive behaviour law was elaborated to account for the effects of particle size, temperature and shear rate. The models described the viscosity as a function of the shear rate, as shown in Table 1. The Car-

Table 1. Empirical models for the viscosity of MIM feedstocks.

\begin{tabular}{|c|c|}
\hline Model & Equation \\
\hline $\begin{array}{c}\text { Power-law } \\
\text { (Ostwald de Waele) } \\
\text { Bingham } \\
\text { Herschel and Bulkley }\end{array}$ & $\tau=k \dot{\gamma}^{n}$ \\
Casson & $\tau=\tau_{0}+k \dot{\gamma}$ \\
Sisko & $\tau^{0.5}=\tau_{0}^{0.5}+\mu_{\infty}^{0.5} \dot{\gamma}^{0.5}$ \\
Cross & $\mu=\mu_{\infty}+K \dot{\gamma}^{n-1}$ \\
Carreau & $\frac{\mu-\mu_{\infty}}{\mu_{0}-\mu_{\infty}}=\frac{1}{1+(\lambda \dot{\gamma})^{m}}$ \\
& $\frac{\mu-\mu_{\infty}}{\mu_{0}-\mu_{\infty}}=\left(1+(\lambda \dot{\gamma})^{2}\right)^{\frac{n-1}{2}}$ \\
\hline
\end{tabular}

$\tau$ is the shear stress $(\mathrm{Pa}), k$ is the flow consistency index $\left(\mathrm{Pa} \cdot \mathrm{s}^{\mathrm{n}}\right), \dot{\gamma}$ is the shear rate $\left(\mathrm{s}^{-1}\right), n$ is the flow behaviour index $(-), \tau_{0}$ is the yield stress $(\mathrm{Pa}), \mu_{\infty}$ is the apparent viscosity to a very high shear rate (Pa.s), $\mu_{0}$ is the apparent viscosity at zero shear (Pa.s), $\lambda$ is the (Cross) time constant (s) and $m$ is the Cross rate constant (-). 
D. Claudel et al.: Material characterisation to identify the rheological behaviour for powder injection moulding

reau-Yasuda model is a generalized model of the Carreau model in which the exponent 2 is replace by a parameter $a$ [11]. This model allows the best transition from the Newtonian threshold at low shear rates to the power-law model. This model was selected to be part of the complex model. However, identification of the power-law model was previously realised to determine the index $n$ of the flow behaviour. Then, the Arrhenius model allowed observation of the thermal influence on the viscosity of the feedstock. A term depending on the particle size previously used by Senapati et al. and Hidalgo [12] was also added to the model. Thus, the generalised constitutive law applied for injection moulding is described by Eq. (1).

$\eta=10 \frac{C u}{D_{50}} \exp \left(\frac{E_{a}}{R T}\right) \eta_{0}\left((1+\lambda \dot{\gamma})^{a}\right)^{\frac{n-1}{a}}$

where $\eta$ is the viscosity. $C u$ is the ratio $D_{60} / D_{10} . D_{10}, D_{50}$ and $D_{60}$ are the particle sizes at 10 vol.\%, 50 vol.\% and $60 \mathrm{vol} \%$ of cumulative volume percentage, respectively. $E_{\mathrm{a}}$ is the Arrhenius activation energy $\left(\mathrm{kJ} \cdot \mathrm{mol}^{-1}\right) . R$ is the perfect gas constant $\left(\mathrm{J} \cdot \mathrm{K}^{-1} \cdot \mathrm{mol}^{-1}\right) . T$ is the temperature $(\mathrm{K}) . \eta_{0}$ is the shear viscosity at zero shear rate $(\mathrm{Pa} \cdot \mathrm{s}) . \lambda$ is the (Cross) time constant. $\gamma$ is the shear rate $\left(\mathrm{s}^{-1}\right) . n$ and $a$ are two parameters to be identified through the experimental measurements.

\section{Experimental procedure}

\subsection{Powder}

Nickel-chromium-based superalloy is used for high-temperature and high-performance applications, particularly in aeronautic industries. The chemical composition is shown in Table 2. Because of its high cost, the reduction of waste material is very important [13]. MIM is a good choice because it has minimal material waste.

A scanning electron microscopy (SEM) image of the pure Inconel powder is shown in Fig. 1. The particles were quasi-spherical. This type of particle shape is ideal for powder injection moulding.

Table 2. Chemical composition of the Inconel superalloy powder provided by Sandvik Osprey.

\begin{tabular}{|c|c|}
\hline Material & Content (wt.\%) \\
\hline $\mathrm{Ni}$ & 53.2 \\
$\mathrm{Cr}$ & 20 \\
$\mathrm{Fe}$ & Bal. \\
$\mathrm{Nb}$ & 4.87 \\
$\mathrm{Mo}$ & 3.24 \\
$\mathrm{Ti}$ & 0.68 \\
$\mathrm{Al}$ & 0.32 \\
$\mathrm{Cu}$ & 0.02 \\
$\mathrm{Si}$ & 0.24 \\
$\mathrm{Mn}$ & 0.14 \\
$\mathrm{~B}$ & 0.001 \\
\hline
\end{tabular}

\subsection{Binder}

A binder system of multi-components was used to elaborate the feedstock. The binder composition is presented in Table 3 . The relative volumetric fraction of powder was approximately $70 \mathrm{vol} \%$. The surfactant in the binder acted as lubricant that enhanced the dispersion of the powder in the binder during mixing. The surfactant also enhanced the powder loading and green strength without compromising the flow properties of the mixture.

\subsection{Description of the mixing test}

The mixing of the binder and powder was realised by a twin-screw Brabender ${ }^{\circledR}$ Plastograph EC mixer. The maximum capacity of the mixing chamber was $55 \mathrm{~cm}^{3}$. The mixing torque was measured and recorded by software. The tests were repeated several times with the same processing conditions: $175^{\circ} \mathrm{C}$ mixing temperature, 30 min mixing time and $30 \mathrm{rpm}$ rotation speed.

The powder was added to the molten binder when its temperature stabilised at the required value. The mixing made the feedstock homogeneous. The homogeneity of the mixture could be evaluated by the evolution of the mixing torque. When the torque reached a stable value, uniform mixing was achieved [14]. Then, the feedstock was granulated in pellets for easy handling in the subsequent procedures.

An SEM image of the Inconel feedstock is shown in Fig. 2. It could be observed that the powder particles were wrapped by the binder.

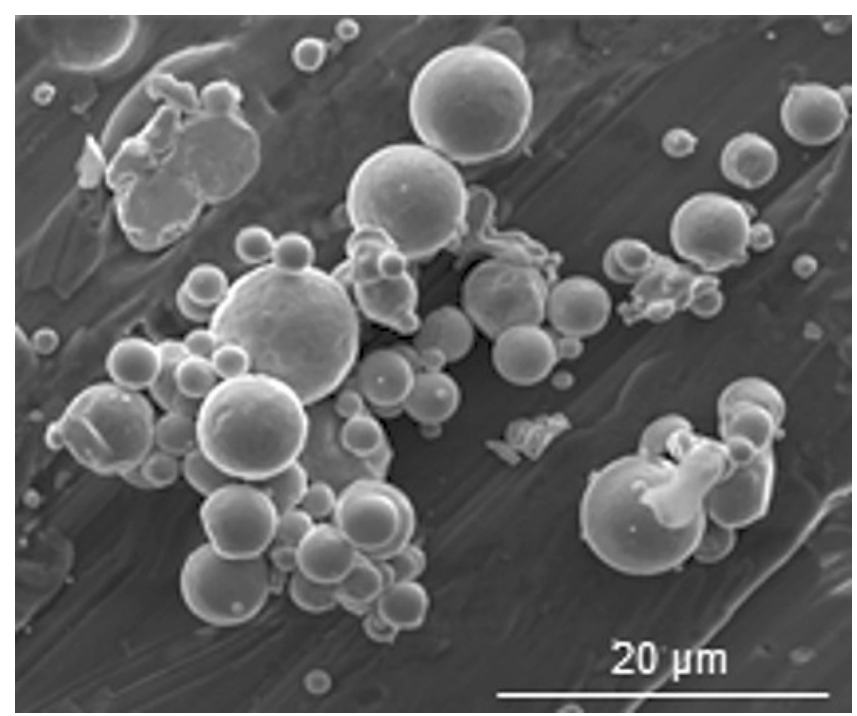

Fig. 1. SEM image of the Inconel powder.

Table 3. Binder composition.

\begin{tabular}{|c|c|c|c|}
\hline Component & PP & PEG & SA \\
\hline $\begin{array}{c}\text { Volumetric fraction } \\
\text { (vol.\%) }\end{array}$ & 40 & 55 & 5 \\
\hline
\end{tabular}




\subsection{Feedstock rheology and particle size}

The rheological properties of the feedstock were characterised using a capillary rheometer. The rheometer barrel was heated to 170,180 or $190^{\circ} \mathrm{C}$, which was higher than the melting temperature of the binder. Then, the binder granules were filled in. A piston was applied with slight pressure for 5-10 min to achieve a homogeneous temperature throughout the materials. Then, the binders were extruded through several tungsten carbide dies of $0.5,1$ and $2 \mathrm{~mm}$ diameters with 8,16 and $32 \mathrm{~mm}$ lengths, respectively. The $L / D$ ratio should be the same to keep the same shear conditions for different dies. Using dies of different sizes allowed broadening of the measurement range by varying the shear rate in a range as large as possible. In fact, the die with a diameter of $0.5 \mathrm{~mm}$ allowed us to measure viscosities for shear rates up to $5.10^{3} \mathrm{~s}^{-1}$. The die with a diameter of $1 \mathrm{~mm}$ was used to measure shear rates between $1.10^{2}$ and $1.10^{4} \mathrm{~s}^{-1}$. The die with a diameter of $2 \mathrm{~mm}$ was used to measure shear rates between 2 and $2.10^{3} \mathrm{~s}^{-1}$ Then, the curves determined by each die were collected together to form only one curve. The viscosity of the binder was measured over a wide range of shear rates from $10^{0}$ to $10^{5} \mathrm{~s}^{-1}$.

The particle size distribution was measured with a laser scattering particle analyser in wet conditions.

\section{Results and discussion}

\subsection{Mixing step}

Figure 3 shows the variation of the mixing torque applied on the mixing screw during the mixing step. The optimal mixing duration could be determined from this curve. This parameter corresponded to the duration of time to obtain a stable mixing torque. The stability of the mixing torque corresponded to a process duration of approximately $30 \mathrm{~min}$. The feedstock was considered to be homogeneous after this time [15].

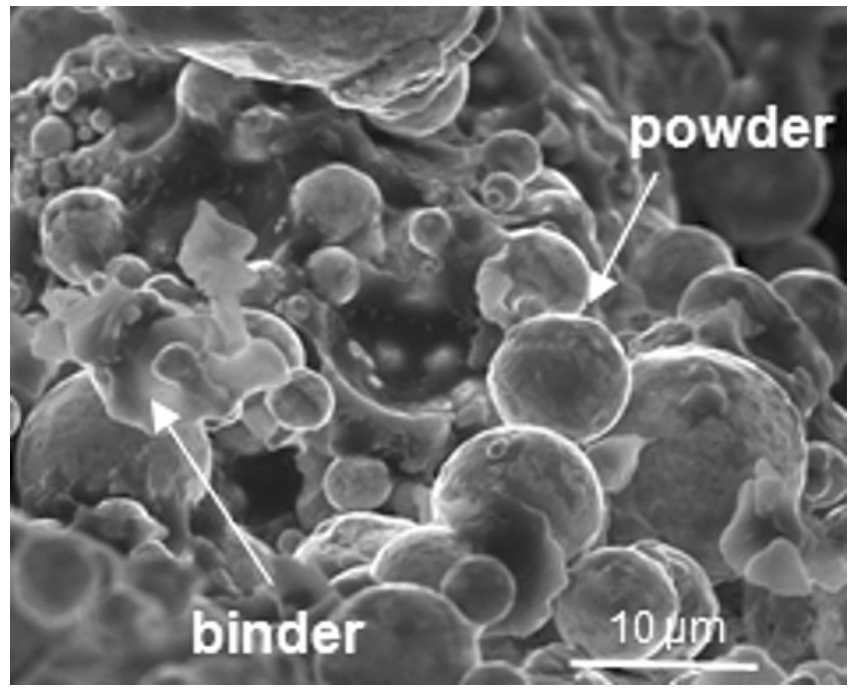

Fig. 2. SEM image of the Inconel superalloy feedstock after the mixing stage (70 vol. $\%$ powder and 30 vol. $\%$ PP/PEG/SA)

\subsection{Homogeneity of the feedstock}

Rheological analysis of the feedstock was carried out at a constant shear rate $\left(50 \mathrm{~s}^{-1}\right)$ using a capillary rheometer. The results of this analysis can be observed in Fig. 4. The viscosity measured vs. time was relatively constant. This result confirmed that the Inconel feedstock was homogeneous after the mixing step [16].

\subsection{Powder particle size}

Figure 5 illustrates the particle size distribution of Inconel superalloy powders in volume. The diameter values corre-

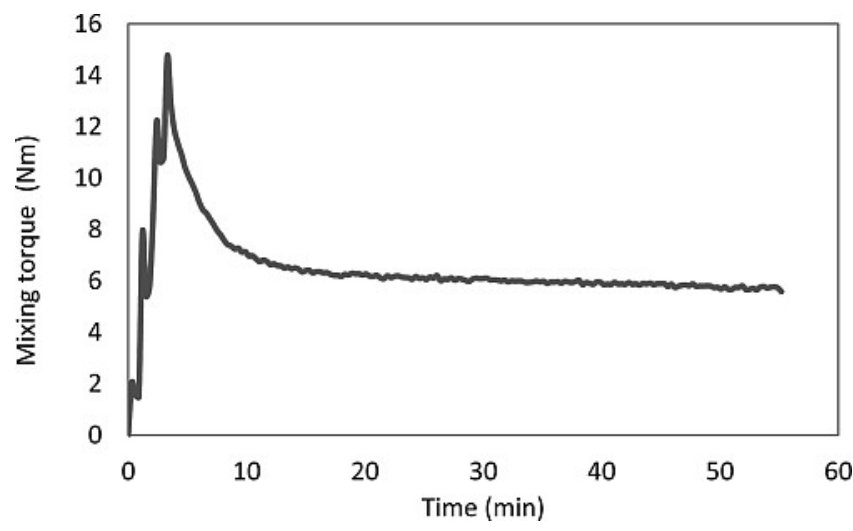

Fig. 3. Mixing torque evolution vs. time for Inconel feedstock elaboration.

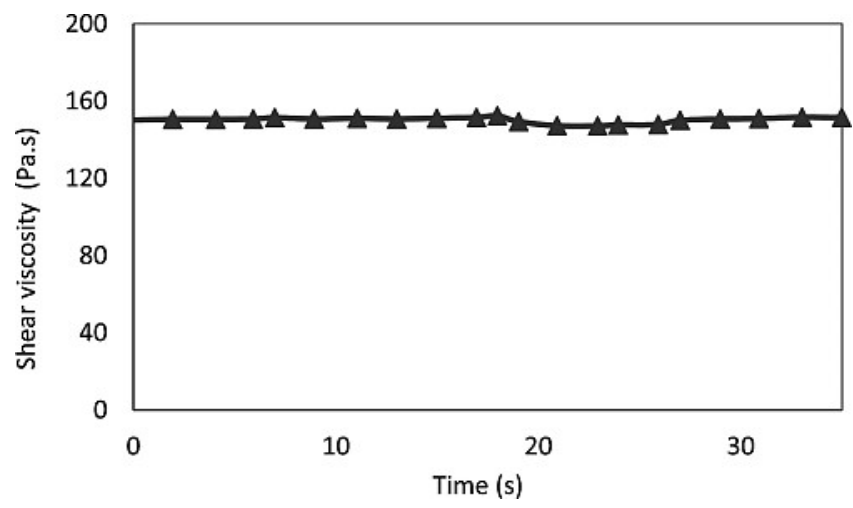

Fig. 4. Inconel feedstock apparent shear viscosity vs. time measured using a capillary rheometer.

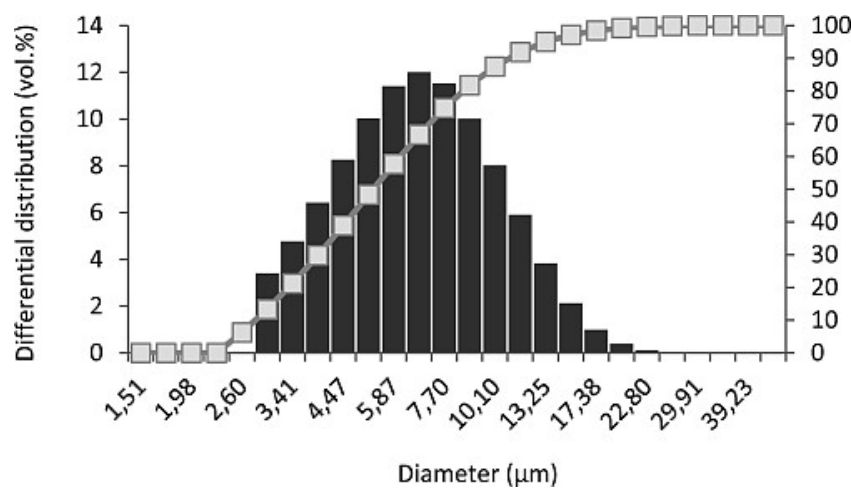

Fig. 5. Particle size distribution for Inconel superalloy powders. 
D. Claudel et al.: Material characterisation to identify the rheological behaviour for powder injection moulding

sponded to cumulative volume fractions $D_{10}, D_{50}$ and $D_{90}$ of $3.53 \mu \mathrm{m}, 6.24 \mu \mathrm{m}$ and $10.97 \mu \mathrm{m}$, respectively. The standard deviation was $0.86 \mu \mathrm{m}$.

\subsection{Apparent viscosity}

The results of the viscosity measurements for the elaborated feedstock are presented in Fig. 6. The feedstock exhibited pseudo-plastic flow behaviour. The viscosity decreased as the shear rate was increased to the test temperatures. This viscosity was plotted for the measurements at 170, 180 and $190^{\circ} \mathrm{C}$.

3.5. Identification of the rheological parameters

The viscous behaviour of feedstock was first identified using a power-law model. The powder index $n$ was deter- mined to be 0.36 . The experimental values for shear rates larger than $10^{3} \mathrm{~s}^{-1}$ were used for the identification.

Then, a more precise identification was made using the generalised constitutive model given in Fig. 7. This model fitted well with the experimental values. The identified parameters are provided in Table 4.

In the Arrhenius equation, described by Eq. (2), from which the thermal term was extracted, a constant $B$ existed. When the temperature was modified, this constant was also modified. For this reason, other parameters, such as $\eta_{0}, a$ and $\lambda$, were modified with temperature in the generalised constitutive model.

$\eta=B \exp \left(\frac{E_{a}}{R T}\right)$
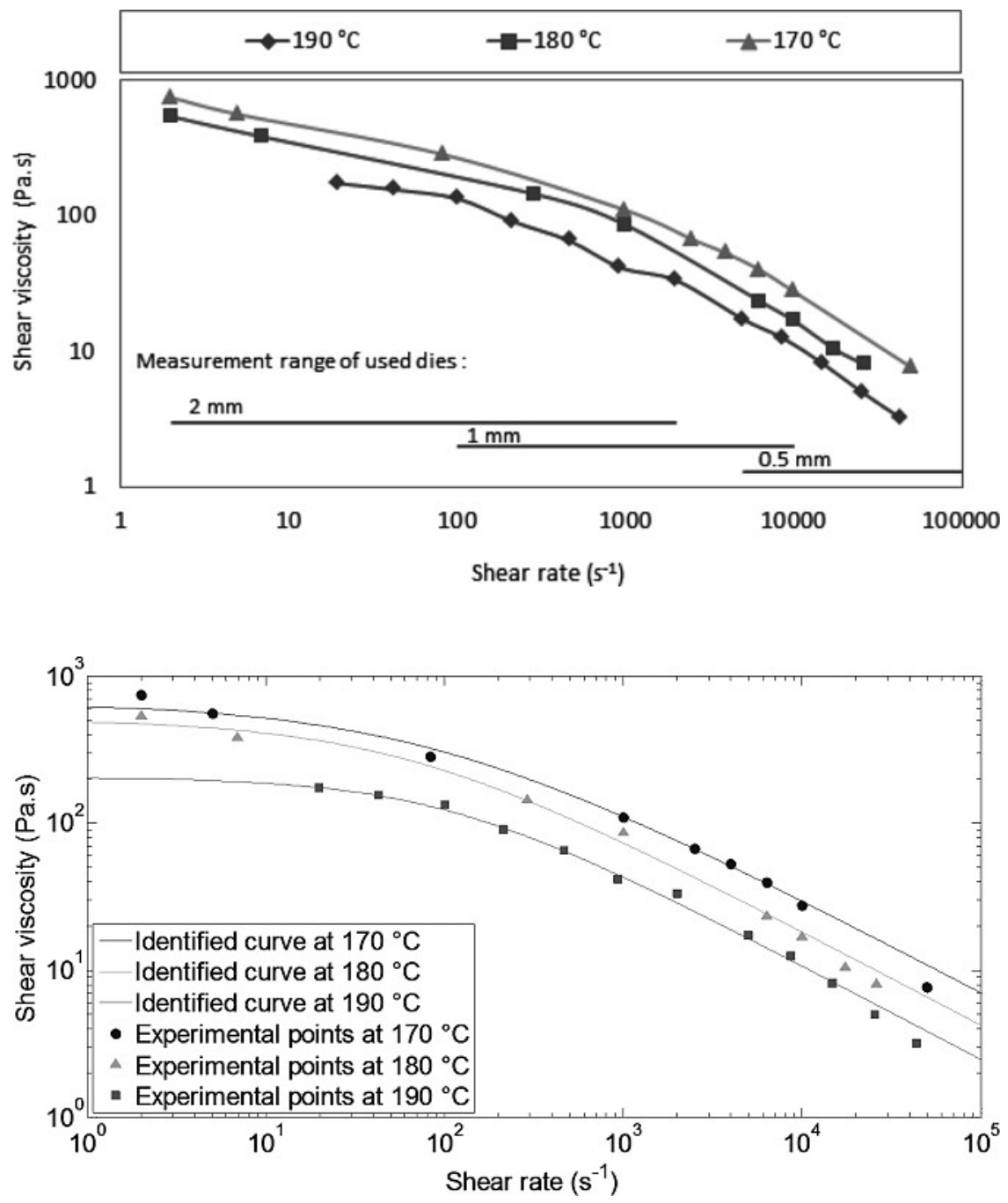

Fig. 6. Variation of the feedstock shear viscosity at different temperatures, 170,180 and $190^{\circ} \mathrm{C}$, measured using three capillary dies.

Fig. 7. Shear viscosity for the Inconel feedstock represented by the complex model with identified parameters and the corresponding values obtained by experiments.

Table 4. Parameters used in the constitutive law model.

\begin{tabular}{|c|c|c|c|c|c|c|}
\hline$T\left({ }^{\circ} \mathrm{C}\right)$ & $a$ & $\lambda(\mathrm{s})$ & $\eta_{0}(\mathrm{~Pa} \cdot \mathrm{s})$ & $n$ & $E_{\mathrm{a}}\left(\mathrm{kJ} \cdot \mathrm{mol}^{-1}\right)$ & $R$-square \\
\hline 170 & 0.6148 & 0.01190 & 207.5 & 0.36 & 20 & 0.9906 \\
180 & 0.7344 & 0.01755 & 158.9 & 0.36 & 20 & 0.9767 \\
190 & 0.8591 & 0.00995 & 64.5 & 0.36 & 20 & 0.9976 \\
\hline
\end{tabular}


D. Claudel et al.: Material characterisation to identify the rheological behaviour for powder injection moulding

\section{Conclusions}

The determination of rheological parameters from the data obtained through standard viscosimetric flow opens the possibility of building reliable analytical models. These models can then be used in injection simulations. The present work allowed the identification of the rheological parameters associated with a nonlinear constitutive equation. A robust analysis was used to determine the constitutive coefficient values based on the experimental data obtained by rheological tests.

The aim of this work was to examine a complex constitutive model. This model provided a more accurate description of the effects of the shear rate and temperature on the feedstock behaviour in large shear rate ranges.

\section{References}

[1] Ö. Özgün, H. Özkan Gülsoy, R. Yilmaz, F. Findik: J. Alloys Compd. 546 (2013) 192. DOI:10.1016/j.jallcom.2012.08.069

[2] C. Quinard, J. Song, T. Barriere, J.C. Gelin: Powder Technol. 208 (2011) 383. DOI:10.1016/j.powtec.2010.08.033

[3] T.S. Shivashankar, R.K. Enneti, S.-J. Park, R.M. German, S.V. Atre: Powder Technol. 243 (2013) 79. DOI:10.1016/j.powtec.2013.03.037

[4] M. Belgacem, B. Thierry, J.C. Gelin: Powder Technol. 235 (2013) 192. DOI:10.1016/j.powtec.2012.10.006

[5] F. Sommer, H. Walcher, F. Kern, M. Maetzig, R. Gadow: J. Eur. Ceram. Soc. 34 (2014) 745. DOI:10.1016/j.jeurceramsoc.2013.09.020

[6] S. Ahn, S.J. Park, S. Lee, S.V. Atre, R.M. German: Powder Technol. 193 (2009) 162. DOI:10.1016/j.powtec.2009.03.010

[7] V.V. Bilovol, L. Kowalski, J. Duszczyk, L. Katgerman: J. Mater. Process. Technol. 178 (2006) 194. DOI:10.1016/j.jmatprotec.2006.03.163

[8] I.U. Mohsin, C. Gierl, H. Danninger: Int. J. Refract. Met. Hard Mater. 29 (2011) 532. DOI:10.1016/j.jirmhm.2011.03.006

[9] N. Ratkovich, W. Horn, F.P. Helmus, S. Rosenberger, W. Naessens, I. Nopens, T.R. Bentzen: Water Res. 47 (2013) 463. DOI:10.1016/j.watres.2012.11.021

[10] P.K. Senapati, B.K. Mishra, A. Parida: Powder Technol. 197 (2010) 1. DOI:10.1016/j.powtec.2009.07.005
[11] K.Y. Yasuda, R.C. Armstrong, R.E. Cohen: Rheol. Acta 20 (1981) 163. DOI:10.1007/BF01513059

[12] J. Hidalgo Garcia: Development of binder systems based on CAB for powder injection moulding and micro powder injection of Zircon and Invar powders, Carlo III University, Spain (2013).

[13] J. Lambarri, J. Leunda, V. García Navas, C. Soriano, C. Sanz: Opt. Lasers Eng. 51 (2013) 813. DOI:10.1016/j.optlaseng.2013.01.011

[14] R. Supati, N.H. Loh, K.A. Khor, S.B. Tor: Mater. Lett. 46 (2000) 109. DOI:10.1016/S0167-577X(00)00151-8

[15] L. Liu, N.H. Loh, B.Y. Tay, S.B. Tor, Y. Murakoshi, R. Maeda: Mater. Charact. 54 (2005) 230. DOI:10.1016/j.matchar.2004.11.008

[16] R.Y. Wu, W.C.J. Wei: J. Eur. Ceram. Soc. 24 (2004) 3653. DOI:10.1016/j.jeurceramsoc.2003.11.027

(Received September 2, 2014; accepted April 30, 2015)

\section{Correspondence address}

Pr. Barriere Thierry

24, chemin de l'épitaphe

25000 Besançon

France

Tel.: +33381666075

Fax:

E-mail: thierry.barriere@univ-fcomte.fr

\section{Bibliography}

DOI 10.3139/146.111265

Int. J. Mater. Res. (formerly Z. Metallkd.)

106 (2015) E; page $1-5$

(C) Carl Hanser Verlag $\mathrm{GmbH} \& \mathrm{Co} . \mathrm{KG}$

ISSN 1862-5282 